\title{
The Causal Relationship Model of Life Skills and Risk Behavior of Undergraduate Students in Thailand
}

\author{
Wichuda Kijtorntham ${ }^{1}$ \\ ${ }^{1}$ Behavioral Science Research Institute, Srinakharinwirot University, Bangkok, Thailand \\ Correspondence: Wichuda Kijtorntham, Behavioral Science Research Institute, Srinakharinwirot University, 114 \\ Sukumvit 23 Klongtoeinuea Wattana Bangkok 10110, Thailand. Tel: 66-2-649-5000. E-mail: \\ wichudak@swu.ac.th
}

Received: October 11, 2012 Accepted: November 2, 2012 Online Published: December 31, 2012

doi:10.5539/ass.v9n1p105

URL: http://dx.doi.org/10.5539/ass.v9n1p105

\begin{abstract}
The purposes of this research were to develop and validate a causal relationship model between life skills and risk behavior of undergraduate students in Thailand. The 4,057 samples of undergraduate students were selected by stratified random sampling technique and completed rate of responding was 67.62 percentages. The self-administered questionnaire was applied, comprised of 5 parts: 1) biosocial factors, 2) perception about benefits of health behavior practicing 3) life skills, 4) health behavior and 5) risk behavior. The reliability of research instrument ranging from 0.7587 to 0.9843 . The development model was properly fitted with the empirical data; $\chi^{2} / \mathrm{df}=3.21, \mathrm{GFI}=0.99, \mathrm{RMR}=0.022, \mathrm{CFI}=0.99$, and AGFI $=0.98$. The model revealed the strongest factor affected risk behavior of undergraduate students was life skills which negative directed effect of 20 percentages. The perception of health promoting practices factor had 72 percentages of positively directed effect on health behavior.
\end{abstract}

Keywords: life skills, risk behavior, health behavior, undergraduate, Thailand

\section{Introduction}

According to the Promotion of Child and Youth Development Act, B.E. 2550 (2007), the Royal Thai Government organized various activities to development of the potential of youth in the areas of health, intellect, social responsibility, and community and social participation (Department of International Organizations, Ministry of Foreign Affairs, 2011). The rapidly changing in global social and economic remained the major barriers to youth development. The study of the Child-Watch Project in Thailand found that Thai youth were victims of economic development, lost the social dependence, and had weak family. In long-term impacts: youth would sumptuous lifestyle, violence, drinking and smoking, which affected the future society having the tendency of more weakness especially family (Masathienwong, 2007). Not only the report on happy and healthy living in the Thai society, but also the report on Thailand's social conditions in the third quarter of 2007 revealed increasing rate of crime offenses against property and drug among youth. The synthesis of 18 Thai youth networks reflected a trend of deterioration in terms of quality of life or lack of life skills caused by living in taking advantage society, having stress from the competition in order to overcome the others and to get something which the other incapable to do. In physical health dimension, found the highest alcohol drinking up to $49.72 \%$ in higher education level and the highest smoking up to $23.95 \%$, in vocational level. In mental health dimension, youth aged less than 25 years attempted suicides more, from 29.73 to 33.98 persons per 100,000 persons. The behavioral problem or risk behavior of youth in national level of Thailand were classified into 8 categories: 1) drinking and smoking; 2) gambling; 3) early sex in young ages and sexual services; 4) being the victim of consumer luxuries; 5) controversy and violence; 6) online games addicts; 7) hang out unsuitable entertainment; and 8) drug addicts (Siriwan, 2007).

Behavior is viewed as being affected by, and affecting, multiple levels of influence. (Eun-Ok Lee, 2001). Furthermore, behavior of any living thing is always the result of biological factors interacting with environmental factors (Cartwright, 2000 cited in Hemmens \& Walsh, 2008). Not only of biological factors but also perceived benefits of action - perceptions of the positive or reinforcing consequences of undertaking a health behavior (Pender, 2011). Health behavior is the central concern of health promotion and one of the most important factors of disease, since over $50 \%$ of chronic diseases are potentially preventable. Avoiding tobacco, 
alcohol, and drugs; stopping smoke; conducting exercise or controlling body weight; self-management of and cope with their illness are all health behaviors aimed at health promotion in a variety of settings including schools, worksites, clinical sites, and communities (Eun-Ok Lee, 2001), where as risk behavior contribute to the leading causes of death and disability among youth monitored by Youth Risk Behavior Surveillance System (YRBSS) including behaviors that contribute to unintentional injuries and violence, sexual behaviors that contribute to unintended pregnancy and sexually transmitted diseases, alcohol and other drug use, tobacco use, unhealthy dietary behaviors and inadequate physical activity (CDC, 2011).

Life skills help young people navigate the challenges of everyday life. They enable them to develop into healthy, responsible, and productive (Hanbury \& Malti, 2011). Approach to life skills will enhance young people's ability to take greater responsibility for their own lives by making healthy choices, gaining greater resistance to negative pressures, avoiding risk behaviors and enable to deal effectively with the challenges of everyday life (Moya, 2001 Mangrulkar et al, 2001). The desirable characteristics of Thai youth in the next 10 years which the (Office of the National Economic and Social Development Board (2007) regulated that "children and youth must have state of emotion, moral, virtue, health, learning skills, love, family bond, and know the rights and duties of their own and of the others". The current problems in society caused youth: lack of life skills; impaired quality of life; decreased capacity and capability; which threaten to country development; and the need of having man powers with desirable characteristics especially in higher education levels going to labor market which chance could be both risk factors or supported factors in country development. Although state sectors and the related offices/organizations joint studied to find guidelines of the problem solving and develop capabilities of students in higher education institutions but the study results, in the past, revealed that they still are unable to really reduce the occurred problems. The problem occurrence of undergraduate students had the tendency to be violence and more complicated, that reflected to the uncompleted life skills which could lead to self-developing to be a capable person who in life problem-solving effectively including the self-development in full scale. Therefore, this study had two objectives: 1) to investigate and compare of life skills among different biosocial factors undergraduate students; and 2) to develop and validate the causal relationship model between life skills and risk behavior of undergraduate students. The result would be useful in knowledge-based development of life skills and health of students in order to be the significant power in developing the future of country.

This study based on three concepts: 1) behavior is a result of interaction between biological factors and environmental factors (Cartwright, 2000); 2) life skills defined by Mangrulkar et al (2001) in 3 aspects; and 3) Health Promotion Model of Pender (1966), determined by perception about benefits of health behavior practicing to decrease the risk of development disease from risk behavior, as shown in Figure 1.

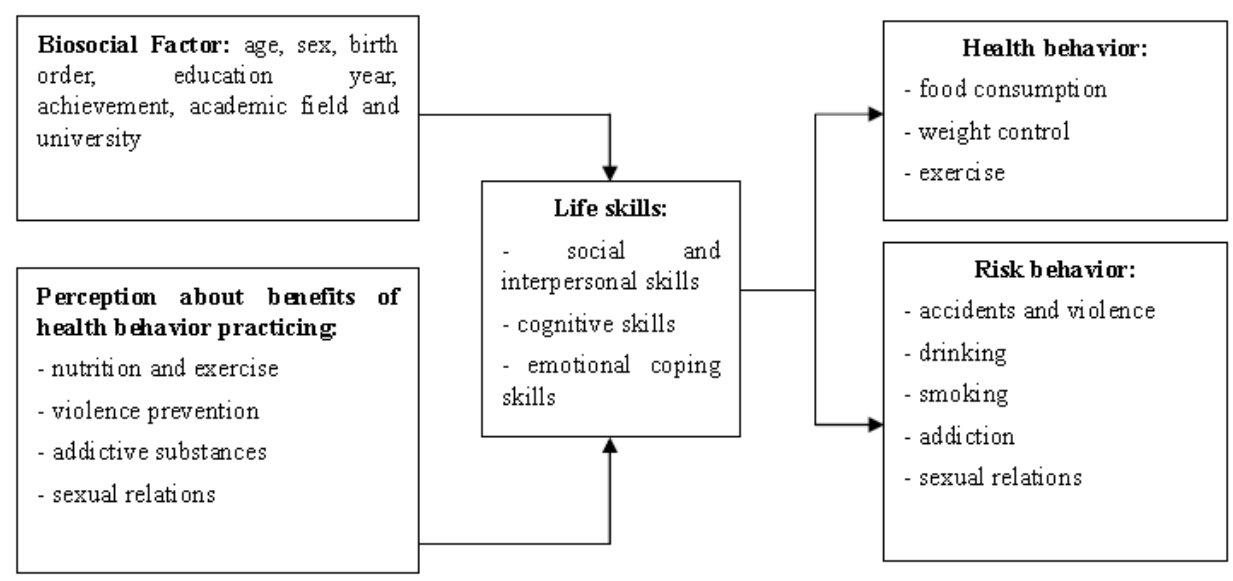

Figure 1. Research framework

The research hypotheses were 1) life skills of undergraduate students will have variance across factors, and 2) The developed causal relationship model between life skills and risk behavior of undergraduate students will fit with the empirical data.

\section{Methods}

This comparative correlational research was conducted in Thailand. The population was undergraduate students from higher education institutions under the Office of the Higher Education Commission, academic year 2010. The stratified random sampling technique was used to select 6,000 undergraduate students from higher education institutions in 6 regions of Thailand: the North Region, the Northeast Region (known as Isan), the Central 
Region, the East Region, the West Region and the South Region of Thailand. The research tool was 5 Likert's rating scale of self-administered questionnaire divided into 5 parts: 1) biosocial characteristics, 2) perception about benefits of health behavior practicing, 3) life skills, 4) health behavior, and 5) risk behavior. The reliability of these research tools by Cronbach's Alpha Coefficient were between 0.7587 to 0.9843 . There were 67.62 percentages of completed questionnaires. The data was analyzed by MANOVA and Structural Equation Model with LISREL program.

\section{Results}

The undergraduate students who answered the questionnaires mostly were female (63.79\%), average age was $20.55,30.69 \%$ was first year of university studies, collective grade point average between 2.01-2.50, study in Sciences was $22.68 \%$, and $56.57 \%$ of them were in state universities.

The undergraduate students obtained high level of life skills (mean $=3.58, \mathrm{SD}=0.40$ ); and had high level of all aspects mostly in cognitive skills (mean $=3.84, \mathrm{SD}=0.54$ ), and more in emotional coping skills (mean $=3.74$, $\mathrm{SD}=0.57$ ). On the other hand, they had low level of health behavior and risk behavior (mean $=2.25$ and 1.40 , $\mathrm{SD}=0.86$ and 0.49 respectively). The self-reported of risky behavior revealed higher of accidents and violence behavior (mean $=1.62, \mathrm{SD}=0.62$ ), and the highest of drinking behavior (mean $=1.64, \mathrm{SD}=0.88$ ); while reported of health behavior was at least of exercises (mean $=2.034, \mathrm{SD}=0.92$ ), as shown in Table 1 .

Table 1. Mean and standard deviation of life skills, health behavior, and risk behavior of undergraduate students

\begin{tabular}{lcc}
\hline \multicolumn{1}{c}{ Life skills and behaviors } & Mean & SD \\
\hline Life skills & $\mathbf{3 . 5 8}$ & $\mathbf{0 . 4 0}$ \\
1. Social skills and Interpersonal relationships & $\mathbf{3 . 1 8}$ & $\mathbf{0 . 4 3}$ \\
1.1 communication & 3.78 & 0.68 \\
1.2 assertiveness & 3.01 & 0.69 \\
1.3 empathy & 3.70 & 0.76 \\
1.4 refusal & 4.78 & 0.94 \\
2. Cognitive skills & $\mathbf{3 . 8 4}$ & $\mathbf{0 . 5 4}$ \\
2.1 decision making & 3.82 & 0.60 \\
2.2 problem solving & 3.90 & 0.64 \\
2.3 analytical thinking & 3.79 & 0.58 \\
3. Emotional control skills & $\mathbf{3 . 7 4}$ & $\mathbf{0 . 5 7}$ \\
3.1 stress management & 3.79 & 0.62 \\
3.2 feeling and emotional management & 3.70 & 0.64 \\
3.3 self-controlling & 3.73 & 0.66 \\
Health behavior & $\mathbf{2 . 2 5}$ & $\mathbf{0 . 8 6}$ \\
1. nutrition & 2.57 & 1.08 \\
2. weight control & 2.19 & 1.01 \\
3. exercises & 2.03 & 0.92 \\
Risk behavior & $\mathbf{1 . 4 0}$ & $\mathbf{0 . 4 9}$ \\
1. accidents and violence & 1.62 & 0.62 \\
2. drinking & 1.64 & 0.88 \\
3. smoking & 1.26 & 0.65 \\
5. addiction & 1.30 & 0.55 \\
\hline Nexual relationships & 1.08 & 0.35 \\
\hline
\end{tabular}

Note: Mean $1.00-2.33$ means the low level

Mean 2.34 - 3.66 means the average level

Mean 3.67 - 5.00 means the high level 
The comparative study on life skills among different biosocial factors undergraduate students found that sex, age, achievement and university of students affected to their life skills at .05 level of statistical significance. Furthermore, all 7 aspects of their biosocial characteristics altogether affected to their life skills, at the .05 level of statistical significance (See Table 2).

Table 2. Comparative result of the student life skills which their biosocial factor

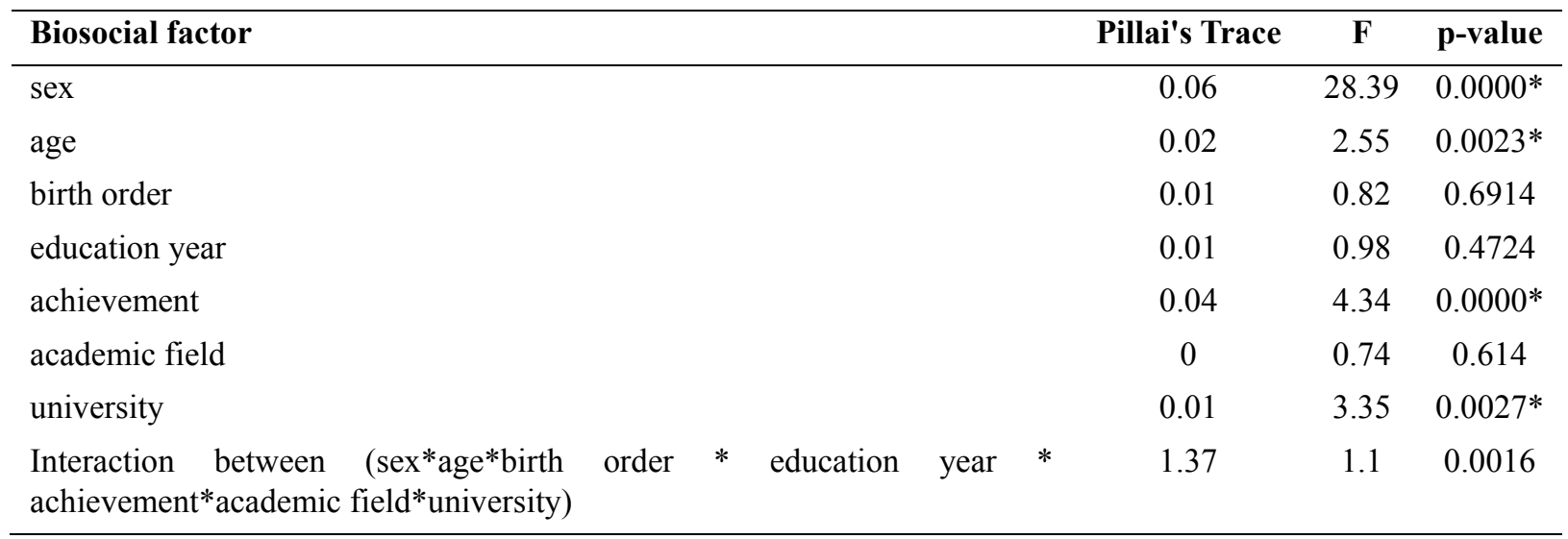

*.05 level of statistical significance.

The development model composed 5 latent factors and 15 observable factors, and was properly fitted with the empirical data determined from the chi-square index divided by the degrees of freedom was less than $5\left(\chi^{2} / \mathrm{df}=\right.$ $3.21)$, goodness of fit index were closed to 1 (GFI $=0.99)$, standardized root mean square residual was less than $.05(\mathrm{RMR}=0.022$, comparative fit index CFI and AGFI were closed to $1(\mathrm{CFI}=0.99, \mathrm{AGFI}=0.98)$.

The effect of observable variables on latent variable shown that the mostly observable variable affected biosocial factor was education year, 54 percentages; while the perception about benefits of health behavior factor was nearly affected by all of its observable variables, about 70-72 percentages. Life skills factor was mostly affected by emotional control skill (47 percentages), health behavior variable was mostly affected by exercise factor (54 percentages), and risk behavior variable was mostly affected by violence ( 37 percentages).

In addition, Life skills factor had 15 percentages of positively directed effect by perception about benefits of health behavior factor, and had 5 percentages negatively directed effect by biosocial factor. Health behavior variable was mostly affected by perception about benefits of health behavior factor, 72 percentages of positively directed effect and 1 percentage of positively indirected effect. Furthermore, risk behavior variable was mostly had 20 percentages negatively affected by life skills factor (See Figure 2).

Table 3. Validity analyses result of the causal model of life skills and risk behavior of undergraduate students

\begin{tabular}{|c|c|c|c|c|c|c|c|c|c|}
\hline \multirow{2}{*}{$\begin{array}{l}\text { Variables/Causal } \\
\text { variables }\end{array}$} & \multicolumn{3}{|c|}{ BIS } & \multicolumn{3}{|c|}{ HKM } & \multicolumn{3}{|c|}{ LS } \\
\hline & TE & IE & DE & TE & IE & $\mathbf{D E}$ & TE & IE & DE \\
\hline HBE & - & - & - & $\begin{array}{c}0.73 \\
(16.56)\end{array}$ & $\begin{array}{c}0.01 \\
(2.19)\end{array}$ & 0.72 & $\begin{array}{c}0.05 \\
(2.21)\end{array}$ & - & 0.05 \\
\hline RBE & - & $\begin{array}{c}0.01 \\
(2.52)\end{array}$ & - & - & $\begin{array}{l}-0.03 \\
(-6.13)\end{array}$ & - & $\begin{array}{l}-0.20 \\
(-8.39)\end{array}$ & - & -0.20 \\
\hline LS & $\begin{array}{c}-0.05 \\
(-2.62)\end{array}$ & - & -0.05 & $\begin{array}{c}0.15 \\
(8.16)\end{array}$ & - & 0.15 & - & - & - \\
\hline Statistics: $\chi^{2}=\mathbf{5 7 4}$ & $=179, p$ & $0, \mathrm{C}$ & 0.99 & GFI $=\mathbf{l}$ & RMR & 22 & & & \\
\hline
\end{tabular}




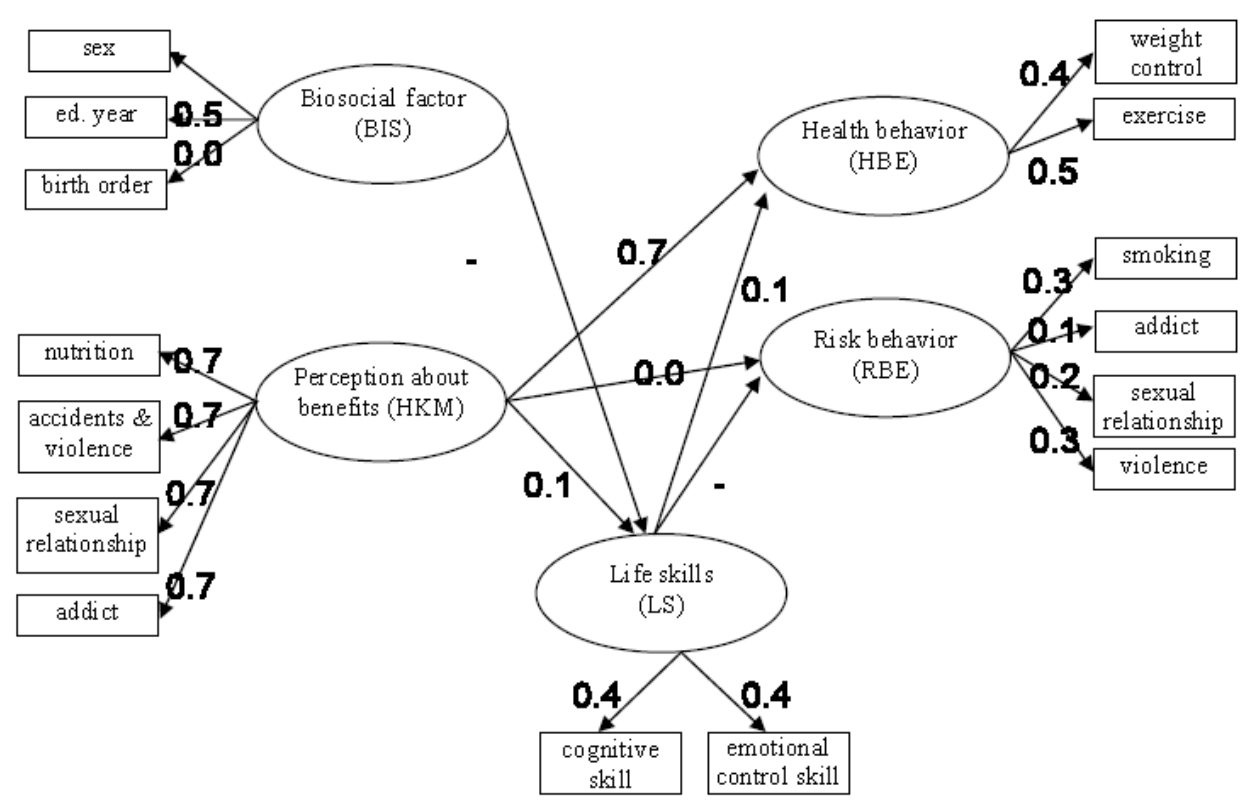

Figure 2. The causal relationship model of life skills and risk behavior of undergraduate students

\section{Discussion}

This research result showed that students who had different biosocial factor consisted of sex, age, achievement and university were going to have different life skills. In Thai culture male and female have different role and duties; female had grown up in the cultural environment that made them familiar with such practices since they were young. When they growing up to university it is time to free their life from their parents both of male and female, but their parents still support all their income on luxury items, traveling, and other non-essential expenses. According to Danish and Hale (1981 cited in Gomes \& Marques, 2012), life skills are learned and become more automatic through demonstration, modeling and practice. Furthermore, the change in a vital stage of life and growth, the period of transition from childhood to adulthood, from family to school and university, from their parents to peers; all of those made them learned and developed their life skill in different way. The positive and negative of parenting experiences were going to effect to all their life, although all parents want what is best for their children, what is best surely varies among parents of different cultures (or subcultures) and also as a function of other factors for people within the same culture, such as socioeconomic status (SES), which is usually measured in terms of income, number of years of education, or occupational status. Parents may also have different beliefs about parenting and child development, such as how competent or independent children should be at different ages and what a parent's role should be in influencing development. What those specific values are and how they are achieved varies among cultures, within cultures, and within parents over time. (Sigel \& McGillicuddy-DeLisi, 2002 cited in Bjorklund \& Blasi, 2012). Too much closed rearing caused no learning from the real social conditions, the life skills were not high. These were the same as the different age range which certainly revealed the past life experiences which had been increasingly (UNFPA, 2005); especially in Thai social context which paid attention to the closed child-rearing. Mostly, they gave their children no opportunities to work for earning a living. In education, parents supported their children until the first degree graduation. Therefore, youth groups were mostly lack of the various social skills. These were different from the Western society which parents allowed their children earn a living from the teen-aged period. All of these showed that the differences in individual were reflected to all social skills which were correlated with the Steinberg (1996) stated that the environmental characteristics of teen-agers effected to skills: found that characteristics of education institution, family, friend group, and the different activities of teen-agers were going to affect their social skills differently. However, in this research, there were no findings that students in different education class levels had the different social skills because the education system in Thai society emphasized the family support. Therefore students in education class level 1-4 (indifferent age period), experienced the similar society, and had indifferent social skills (Jiemnakin, 1996).

The testing of causal relationship model between life skills and risk behavior of undergraduate students revealed properly fitting to the empirical data. It showed that using Health Promotion Model (Pender, 1996) could explain Thai society which found that undergraduate students had perception about benefits of health behavior effecting to the life skills and the health behavior. Therefore these revealed the influences of learning and experiencing 
were going to affect undergraduate students to be able to predict the results to them by themselves; therefore the health behaviors were increased.

\section{Recommendation}

\subsection{Recommendation to the Research Result Usage}

This research result showed that the related factors to the risk behavior of undergraduate students \consisted of internal factors which were occurred from the bio-social characteristics and external environment factors. The developed life skills were going to one way to lessen the risk behavior of undergraduate students which should be done: 1) undergraduate students' health behavior promotion by building up the more awareness of the useful health behavior practices; and 2) should develop the undergraduate students' life skills in emotional control combine with cognitive skills for lessening the risk behaviors, significantly in accidents, violence, cigarette smoking and sex relationships.

\subsection{Recommendation to the Next Research}

This research result showed that undergraduate students still had the awareness of the useful health behavior practices in the low level. Therefore it should have a research for evaluating the needs of promoting the undergraduate students' awareness of the useful health behavior practices in the bio-social characteristics and external environment differences; the research for developing the model of health behavior promotion with various bio-social characteristics and external environments status.

\section{Acknowledgements}

The research project was supported by the Office of the Higher Education Commission and the Thailand Research Fund, fiscal year 2009; and was kindly assisted from Professor Pruet Siribanphitak, Ph.D. to be the project advisor.

\section{References}

Bjorklund, D. F., \& Blasi, C. H. (n. a.). Understanding Life Skills. Retrieved from http://www.cbse.nic.in/cce/life_skills_cce.pdf

Centers for Disease Control and Prevention. (2011). Youth Risk Behavior Surveillance. Retrieved from http://www.cdc.gov/mmwr/pdf/ss/ss6104.pdf

Department of International Organizations, Ministry of Foreign Affairs. (2011). Thailand's Implementation of the United Nations Resolution 641134 - Proclamation of 2010 as the International Year of Youth: Dialogue and Mutual Understanding Activities in relation to the International Year of Youth in Thailand. Retrieved from http://www.mfa.go.th/humanrights/implementation-of-un-resolutions/149-activities-in-relation-to-the-intern ational-year-of-youth-in-thailand

Gomes, A. R., \& Marques, B. (2012). Life skills in educational contexts: testing the effects of an intervention programme. Retrieved from http://www.tandfonline.com/loi/ceds20

Hanbury, C., \& Malti, T. (n. a.). Monitoring and Evaluating Life Skills for Youth Development. Retrieved from http://www.jacobsfoundation.org/.../Jacobs_ME_Guideline_e

Hemmens, C., \& Walsh, A. (2008). Introduction to Criminology: A Text/Reader. LA: Sage Publications.

Jiemnakhin, P. (1996). Adolescence development. Bangkok: Conform Co. Ltd.

Lee, Eun-Ok. (2001). Health promotion for the chronic patients. Retrieved from http://www.oita-nhs.ac.jp/journal/PDF/2_2/2_2_2.pdf

Mangrulkar, L. M., Whitman, C. V., \& Posner, M. (2001). Life Skills Approach to Child and Adolescent Healthy Human Development. Retrieved from http://www.paho.org/english/hpp/hpf/adol/lifeskills.pdf

Masathienwongs, J. (2007). Thai children on the three-way routes: the syntheses of case-study about children and youth in each province. Bangkok: Office of the Thailand Research Fund (TRF) and the Health Promotion Office (HPO).

Moya, C. (2001). Life Skills Approaches to Improve Young Adult Reproductive. Retrieved from http://ceria.bkkbn.go.id/ceria/referensi/artikel/detail/117

Office of the National Economic and Social Development. (2007). Thai Youth Desirable Values in the Next 10 Years. Retrieved from http://www.nesdb.go.th/ 
Pender, N. J. (1996). Health Promotion in Nursing Practice (3rd ed.). Stanford, CT: Appleton \& Lange.

Pender, N. J. (2011). The Health Promotion Model: Manual. Retrieved from http://deepblue.lib.umich.edu/bitstream/2027.42/85350/1/HEALTH_PROMOTION_MANUAL_Rev_5-201 1.pdf

Sirewan, Y. (2008). Sadly reveal 8 teen-age problems: the high rate of child suicide. Retrieved from http://www.thaihealth.or.th/healthcontent/article/4399

Steinberg. (1996). Child \& Adolescent Development: An Integrated Approach. Balmont, CA: Wadsworth, Cengage Learning.

United Nations Fund for Population Activities (UNFPA). (2005). Adolescents Fact Sheet. Retrieved from http://www.unfpa.org/swp/2005/presskit/factsheets/facts_adolescents.htm 